Faculdade

de Ciências Econômicas UFRGS
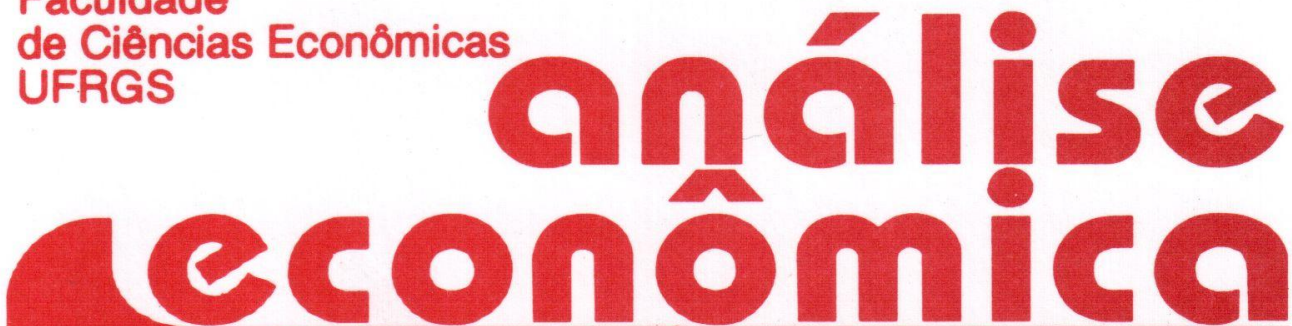

- globalização, Blocos REgIONAIS E O SETOR AGRÍ́COLA NO MERCOSUL Paulo D. Waquil

- globalização: ReALIdAde E UTOPIA

Gentil Corazza

- DO FOREIGN CURRENCY DEPOSITS DID THEY IMPROVE WELFARE?

Carlos A. Janada

- MACROECONOMIC INSTABILITY AND STRATEGIES OF TRANSNATIONAL CORPORATIONS IN BRAZIL

Reinaldo Gonçalves

- INFRASTRUCTURE, PUBLIC CAPITAL AND GROWTH IN THE BRAZILIAN ECONOMY

Stefano Florissi

+ EFEITOS DO PLANO REAL SOBRE O RIO GRANDE DO SUL Marcelo S. Portugal

- REgIONALIZAÇÃo dA MATRIZ dE INSUMO-PRODUTO E O IMPACTO DO AUMENTO DA PRODUÇÃO DE GRÃOS NO RS E NO BRASIL

Nali de Jesus de Souza

- IMPORTACõES DE LEITE E A PECUÁRIÁ LEITEIRA NO BRASIL Silvinha P. Vasconcelos

- ANPEC: CURSO PREPARATÓRIO

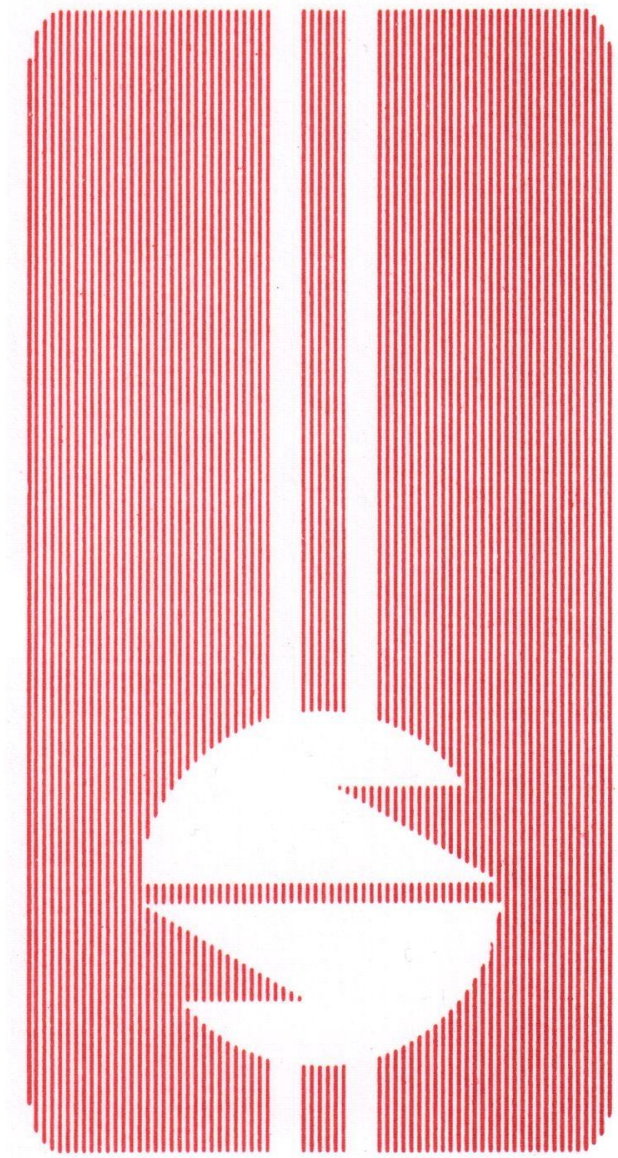


UNIVERSIDADE FEDERAL DO RIO GRANDE DO SUL

Reitor. Prof ${ }^{a}$. Wrana Maria Panizzi

FACULDADE DE CIÊNCIAS ECONÔMICAS

Diretor. Prof'. Otília Beatriz Kroeff Carrion

CENTRO DE ESTUDOS E PEQUISAS ECONÔMICAS

Diretor: Prof. Paulo Alexandre Spohr

DEPARTAMENTO DE CIÊNCIAS ECONÔMICAS

Chefe: Prof. Gentil Corazza

CURSO DE PÓS-GRADUAÇÃO EM ECONOMIA

Coordenador. Prof. Marcelo Savino Portugal

CURSO DE PÓS-GRADUAÇÃO EM ECONOMIA RURAL.

Coordenador. Prof. Carlos Guilherme A. Mielitz Netto

CONSELHO EDITORIAL: Achyles Barcelos da Costa, Aray Miguel Feldens, Carlos Augusto Crusius, Carlos Guilherme A. Mielitz Netto, Eugênio Lagemann, Fernando Ferrari Filho, Gentil Corazza, Marcelo Savino Portugal, Nali de Jesus de Souza, Otília Beatriz K. Carrion, Paulo Alexandre Spohr, Paulo Dabdab Waquil, Pedro Cezar Dutra Fonseca, Roberto Camps Moraes, Valter José Stülp, David Garlow (Wharton Econometrics Forecasts Association, E.U.A.), Edgar Augusto Lanzer (UFSC), Eleutério F. S. Prado (USP), Fernando de Holanda Barbosa (FGV/RJ), Gustavo Franco (PUC/RJ), João Rogério Sanson (UFSC), Joaquim Pinto de Andrade (UnB), Juan H. Moldau (USP), Werner Baer (Univ. de Illinois, E.U.A.).

COMISSÃO EDITORIAL: Fernando Ferrari Filho, Gentil Corazza, Paulo Dabdab Waquil, Marcelo Savino Portugal, Roberto Camps Moraes.

EDITOR: Nali de Jesus de Souza

SECRETARIA: Cláudia Porto Silveira, Jeferson Luis Bittencourt. Revisão de textos: Vanete Ricachescki.

FUNDADOR: Prof. Antônio Carlos Santos Rosa

Os materiais publicados na revista Análise Econômica são da exclusiva responsabilidade dos autores. É permitida a reprodução total ou parcial dos trabalhos, desde que seja citada a fonte. Aceita-se permuta com revistas congêneres. Aceitam-se, também, livros para divulgação, elaboração de resenhas e recensões. Toda correspondência, material para publicação (vide normas na terceira capa), assinaturas e permutas devem ser dirigidos ao seguinte destinatário:

PROF. NALI DE JESUS DE SOUZA

Revista Análise Econômica

Av. João Pessoa, 52

CEP 90040-000 PORTO ALEGRE - RS, BRASIL

Telefones: (051) 316-3348 e 316-3440

Fax: (051) 225-1067 


\section{PROJEÇÃO E REGIONALIZAÇÃO DA MATRIZ DE INSUMO-PRODUTO: IMPACTO DO AUMENTO DA PRODUÇÃO DE GRÃOS NO RS E NO BRASIL NO ANO 2000}

Nali de Jesus de Souza*

\section{SINOPSE}

Este trabalho apresenta a metodologia de obtenção da matriz brasileira de relações intersetoriais na forma de produto, a partir das matrizes setoriais, e a metodologia de projeção e regionalização de matrizes, bem como avalia o impacto de uma variação na produção de grãos de 6 e 30 milhões, respectivamente, sobre o produto e o emprego do Rio Grande do Sul e do Brasil no ano 2000.

\section{INTRODUÇÃO}

O modelo de insumo-produto tem se mostrado de muita utilidade para o estudo comparativo das estruturas produtivas das diferentes economias, tanto no tempo, como no espaço. De posse de uma matriz, pode-se também identificar os setores-chave no encadeamento da produção, do emprego e das exportações líquidas, entre outros objetivos de politica. Da mesma forma, é possivel isolar complexos industriais fortemente conectados, bem como pólos industriais.

Uma outra utilidade da matriz é efetuar simulações setoriais de impactos na produção e no emprego, a partir, por exemplo, da variação da produção de grãos em alguns milhões de toneladas, ou o aumento das exportações em US\$ 5 bilhões. Com o uso da matriz, pode-se ver os produtos mais afetados e identificar pontos de estrangulamentos que, virtualmente, impediriam 0 cumprimento da meta estabelecida (ver Souza, 1996a).

Como a elaboração das matrizes de insumo-produto é muito trabalhosa, envolvendo altos custos, geralmente as matrizes disponíveis são muito velhas, não representando mais a estruturura tecnológica da economia. De outra parte, o

\footnotetext{
* Professor Titular do Departamento de Economia e do Curso de Pós-Graduação em Economia da UFRGS. Doutor pela Universidade de Paris I e pela Universidade de São Paulo. O Autor agradece a colaboração dos estagiários de Iniciação Cientifica do CNPq Jeferson Luís Bittencourt e Cláudia Porto Silveira. O trabalho de Cláudia foi fundamental para a determinação do vetor de produção nacional e regional e aplicação do método R.A.S.
}

\begin{tabular}{|c|c|}
\hline $\begin{array}{c}\text { Cód. } A E A \\
211\end{array}$ & $\begin{array}{c}\text { Palavras-chave: } \\
\text { Insumo-produto, método R.A.S., análise de impactos. }\end{array}$ \\
\hline
\end{tabular}

\begin{tabular}{|l|l|l|l|} 
ANÁLISE ECONÓMICA & ANO 15 & Março, 1997 & p. 110-129 \\
\hline
\end{tabular}


estudo pode envolver uma determinada região (ou Estado da Federação) e o uso de matrizes nacionais podem viesar as conclusōes.

Desse modo, para minimizar esses problemas, desenvolveram-se na literatura alguns métodos de atualização de coeficientes e de regionalização de matrizes nacionais, como o método R.A.S. que será apresentado adiante.

Este trabalho, portanto, tem como objetivos apresentar a metodologia de adaptação das matrizes nacionais de insumo-produto, em termos de atualização e de regionalização dos dados, bem como avaliar o impacto sobre a produção e o emprego de um aumento na produção gaúcha e brasileira de grãos de 6 e 30 milhões de toneladas, respectivamente.

\section{ADAPTAÇÃO DA MATRIZ NACIONAL DE INSUMO-PRODUTO}

O IBGE vem calculando as diferentes matrizes para a economia brasileira desde 1970. ${ }^{1}$ Ele dispõe as matrizes para os anos de 1970, 1975, 1980, 1985, 1990, 1991 e 1992 (estes dois últimos anos estão disponiveis via Internet).

Desde 1985, as matrizes possuem 40 setores e 80 produtos. Para diminuir custos, o IBGE tem reduzido a dimensão das matrizes. Assim, para se ter uma maior desagregação, pode-se trabalhar com produtos, no lugar de setores. Desse modo, para a compatibilização dos dados dos diferentes anos, deve-se agregar as matrizes anteriores em um número menor de setores e produtos. Os 136 produtos da matriz de 1980, por exemplo, foram alocados nos 80 produtos das matrizes mais recentes, a fim de possibilitar a comparação. Para isso; basta agregar os setores e produtos da matriz de acordo com um quadro de correspondência fornecido pelo IBGE.

$\mathrm{Na}$ verdade, cada produto, na maior parte dos casos, constitui uma agregação de produtos de natureza similar e, em suma, eles não passam de "setores" classificados como "produtos". A vantagem dessa operação é ter-se dados mais desagregados e de se trabalhar com um grau maior de detalhamento das relações intersetoriais.

Com base no método R.A.S., pode-se regionalizar uma matriz nacional, assim como projetá-la, obtendo-se coeficientes mais atualizados. Os dados para a matriz do ano terminal podem ser obtidos a partir de índices de crescimento dos diferentes produtos, caso não se tenha o vetor de produção $(80,1)$, para esse mesmo ano.

No mesmo sentido da compatibilização dos dados, precisa-se transformar as matrizes dos coeficientes por setor do IBGE $(40,40)$ em matrizes de coeficientes por produto $(80,80)$.

1 Outras matrizes de relações intersetoriais para a economia brasileira foram as do IPEA (Relações intersetoriais do Brasil, 1967), para o ano de 1959, e a de Leão et al. (1973), para 1970. 
A transformação das matrizes quadradas por setor em matrizes quadradas por produtos, efetua-se através da seguinte metodologia, já empregada em pesquisa anterior (Souza, 1994):

$B(80,40)=U(80,40) G_{d}^{-1}(40,40)$,

onde $U$ é a matriz dos insumos domésticos por setor, $G_{d}$ é o vetor da produção setorial diagonalizada e $B$ é a matriz dos coeficientes técnicos dos insumos domésticos setoriais; a matriz $U$ compreende todos os produtos utilizados como insumos pelo setor respectivo; os números entre parêntesis indicam a ordem da matriz.

$D(40,80)=V(40,80) Q_{d}^{-1}(80,80)$,

onde $V$ é a matriz da produção por setor, segundo todos os produtos; $Q$ é a produção total por produto diagonalizada e $D$ é a matriz dos coeficientes de produto por setor.

$A(80,80)=B(80,40) D(40,80)$,

onde $A$ é a matriz dos coeficientes técnicos de insumo-produto por produto. $A$ matriz $A$ do IBGE, como as demais matrizes de coeficientes, é fornecida por setor, obtida pela multiplicação da matriz $D$ pela matriz $B$, ou seja:

$A^{s}(40,40)=D(40,80) B(80,40)$.

De posse da matriz $A$, pode-se calcular a matriz dos impactos diretos e indiretos de Leontief $(K)$, como segue:

$K=(I-A)^{-1}$,

onde $\mathrm{K}(80,80)$ é a matriz dos impactos diretos e indiretos por produto.

Através da matriz $K$, poder-se-á calcular todos os indices de encadeamento verticais por produto (para trás no processo produtivo).

Os indices de encadeamento horizontais (para frente no processo de encadeamento) precisam ser calculados pela matriz dos coeficientes de produtos, $A^{*}$, que fornece a matriz de Jones, $K^{*}$.

A matriz dos coeficientes $A^{\star}$ é obtida pela divisão de todas as linhas da matriz $W$ pela produção respectiva $\left(Q_{i}\right)$, no lugar das colunas, como se faz no caso dos índices de encadeamento verticais, como foi explicado em trabalhos anteriores (Souza, 1994).

Para se obter a matriz $A^{*}$ por produto $(80,80)$, é necessário obter antes a matriz dos fluxos entre produtos $W(80,80)$, a partir da matriz $A(80,80)$, como segue:

$W(80,80)=A(80,80) Q_{d}{ }^{-1}(80,80)$

$A^{*}(80,80)=Q_{d}{ }^{-1}(80,80) W(80,80)$.

De onde,

$\mathrm{K}^{*}=\left(I-A^{*}\right)^{-1}$ 
Através das matrizes $K(80,80)$ e de $K^{*}(80,80)$, calculam-se todos os indices de encadeamento verticais e horizontais. As metodologias para o cálculo desses indices e para a identificação dos complexos industriais poderão ser encontradas em Souza (1988, 1989, 1995 e 1996a).

\subsection{Obtenção da variável emprego}

Os dados de emprego, fornecido em um vetor $E_{s}(1,40)$, isto é, por setor, podem ser obtidos em um vetor $E_{p}(1,80)$. Esse vetor pode ser calculado, alocando-se o vetor do emprego setorial $E_{s}(1,40)$ pela matriz da produção setorial $D(40,80)$, como segue:

$E_{p}(1,80)=E_{s}(1,40) D(40,80)$

O elemento $d_{i j}$ de $D(40,80)$, obtido pela razão entre as vendas do produto $i$, utilizado como insumo na fabricação do produto $j$, em relação à produção total $Q_{i}$, é um número puro, o qual multiplicado em linha pela quantidade de emprego $E_{s i}$ aloca todos os empregos setoriais em emprego por produto, como segue:

$$
\begin{aligned}
& E_{p 1}=E_{s 1} d_{11}+E_{s 2} d_{21}+E_{s 3} d_{31}+\ldots+E_{s n} d_{n 1} \\
& E_{p 2}=E_{s 1} d_{12}+E_{s 2} d_{22}+E_{s 3} d_{32}+\ldots+E_{s n} d_{n 2} \\
& E_{p 3}=E_{s 1} d_{13}+E_{s 2} d_{23}+E_{s 3} d_{33}+\ldots+E_{s n} d_{n 3} \\
& \ldots \ldots \ldots \ldots \ldots \ldots \ldots \ldots \ldots \ldots \ldots \ldots \ldots \ldots \ldots \ldots \ldots \ldots \ldots \ldots \ldots \ldots \ldots \ldots \ldots \ldots \ldots \ldots \ldots \ldots \ldots \ldots \ldots \ldots \ldots \ldots \ldots \ldots \ldots \ldots \ldots \ldots \\
& E_{p n}=E_{s 1} d_{1 n}+E_{s 2} d_{2 n}+E_{s 3} d_{3 n}+\ldots+E_{s n} d_{n n}
\end{aligned}
$$

Obviamente, a soma do emprego total por produto será igual à soma do emprego total por setor.

\section{O MÉTODO R.A.S. DE PROJEÇÃO E REGIONALIZAÇÃO DE COEFICIENTES}

A grande questão do método R.A.S., utilizado para projetar os coeficientes técnicos da matriz $A$, ou os próprios fluxos intersetoriais da matriz $W$, a partir de um ano base, para uma data futura, ou para regionalizar tais coeficientes ou fluxos, é a determinação precisa do vetor de produção total nacional e regional do ano terminal, por produto $(80,1)$, uma vez que a classificação dos censos econômicos não coincide, necessariamente, com a classificação da matriz de insumo-produto.

De posse da tabela de correspondência, fornecida pelo IBGE, entre a classificação dos censos e a classificação das matrizes, procede-se ao ajuste dos dados regionais. É preciso efetuar-se algumas hipóteses, ao alocar a produção entre os diferentes produtos. Precisa-se, ainda, efetuar-se a calibragem dos dados ajustados, relativos aos produtos, pela produção setorial correspondente, fornecida pelos censos. Essa calibragem tem como objetivo fornecer uma cuerência aos dados e dar uma melhor consistência relativa às interdependências tecnológicas. 
De posse desse vetor $Q^{R}(80,80)$ e da matriz nacional de fluxos por produto $W^{N}(80,80)$, através do método R.A.S, obtém-se a matriz dos fluxos regionais por produto $W^{R}(80,80)$ para o ano desejado (por exemplo, 1995). A partir de $W^{R}(80,80)$ obtêm-se as demais matrizes regionais $A^{R}(80,80)$ e $K^{R}(80,80)$.

A matriz nacional $W^{N}(80,80)$, do ano terminal pode ser calculada a partir do vetor da produção por produto $Q^{N}(80,80)$, obtido a partir de dados publicados ou através de indices de crescimento dos 80 produtos, entre 0 ano base e 0 ano terminal A partir desse vetor e da matriz de fluxo $W^{N}(80,80)$ do ano base, através do método R.A.S., obtém-se a matriz nacional do ano terminal. Em seguida, essa matriz nacional gera a matriz regional do ano terminal, utilizandose igualmente o método R.A.S.

Esse método tem como objetivo ajustar a matriz nacional $W^{N}(80,80)$ pelo vetor da produção regional por produto $Q^{R}(80,80)$, obtendo-se ao final de um processo interativo relativamente longo, que compreende $n$ operações, a matriz dos fluxos regionais por produto $W^{R}(80,80)$.

O primeiro passo do método R.A.S. consiste em estimar a demanda intermediária total da região, de acordo com a seguinte relação:

$D I^{R} / Q^{R}=D I^{N} / Q^{N}$

Através da equação (1), supõe-se que a participação da demanda intermediária regional $\left(D l^{R}\right)$ no produto total da região $\left(Q^{R}\right)$ seja idêntica à participação da demanda intermediária nacional $\left(D I^{N}\right)$ no produto bruto nacional $\left(Q^{N}\right)$. São adotados os mesmos procedimentos e suposição para o cálculo do consumo intermediário regional total $\left(\| I^{R}\right)$, isto é:

\|\|$^{R} / Q^{R}=\| N^{N} / Q^{N}$

Os vetores $D I^{N}$ e $I^{N}$ são colocados, respectivamente, ao lado e abaixo da matriz $W^{N}$ e, ao lado e abaixo destes últimos vetores, os vetores estimados $D I^{R}$ e $\|^{R}$. Finalmente, ao lado e abaixo dos vetores mencionados, arranjam-se os vetores da razão $D I^{R} / D I^{N}$ e $I^{R} / I^{N}$, ou seja:

$\left[W^{N}(80,80)\right]\left[D I^{N}(80,1)\right]\left[D I^{R}(80,1)\right]\left[D I^{R} / D l^{N}(80,1)\right]$

$\left[I^{N}(1,80)\right]$

$\left[I^{R}(1,80)\right]$

$\left[I I^{R} / I^{N}(1,80)\right]$

Deve-se atentar para o fato de que os vetores $D I^{N}(80,1), I^{N}(1,80), D I^{R} / D I^{N}$ $(80,1)$ e $I^{R} / I^{N}(1,80)$ são, respectivamente, a soma das linhas e colunas da matriz $W^{N}$ e duas relações que se tornarão variáveis à medida que o método for interagindo e, como tal, devem permanecer como fórmula de soma [@sum (intevalo de células a ser somado)] e de divisão (+ célula da região/célula do Pais) na planilha do Lotus, para que o método R.A.S. seja aplicado com sucesso. A seguir, copia-se todo o conjunto de matrizes (3), para locais abaixo da planilha do Lotus, para que se tenha dois conjuntos iguais de matrizes para a 
aplicação do método e a realização das interações necessárias até a convergência.

Outro passo fundamental do método, que deve ser efetuado antes de rodar - programa, é o da exclusão das linhas e colunas correspondentes aos produtos inexistentes na região, cuja matriz $W^{R}$ deseja-se estimar. Abaixo dos dois conjuntos de matrizes escreve-se a macrodefinição - um miniprograma interativo que se cria no interior das planilhas para executar tarefas mais complexas - ficando cada comando em uma célula diferente, de preferência um abaixo do outro.

Aplica-se tantas vezes quantas forem necessárias o processo interativo da macrodefinição, de sorte que as razões dos vetores $\left[I^{R} / I^{N}\right]$ e $\left[D l^{R} / D I^{N}\right]$ tendam a convergir à unidade. As multiplicações do processo interativo são repetidas 50 vezes ou mais, até ocorrer a convergência referida.

De posse da matriz $W^{R}$ assim regionalizada, procede-se ao cálculo das matrizes dos impactos diretos $\left(A^{\mathrm{R}}\right)$ e diretos e indiretos de insumo-produto $\left(K^{\mathrm{R}}\right)$. Pode-se, a seguir, calcular os indices de encadeamento da economia regional, identificar complexos industriais regionais e efetuar simulações de impactos regionais e nacionais sobre a produção, emprego etc.

\section{IMPACTOS NA ECONOMIA GAÚCHA E BRASILEIRA DO AUMENTO DA PRODUÇÃO DE GRÃOS NO ANO 2000}

Uma das aplicações possiveis da análise de insumo-produto consiste na análise do impacto de um aumento da produção de algum produto ou grupos de produtos sobre o conjunto da economia. Em pesquisa realizada recentemente, foi estimado o impacto na economia decorrente do aumento de seis milhões de toneladas de grãos no Rio Grande do Sul e trinta milhões no Brasil (arroz, milho, soja e trigo).

Inicialmente, pensou-se em simular a variação da produção gaúcha de grãos em dez milhões de toneladas. Contudo estudando-se a evolução da área cultivada e da produtividade dessas culturas, concluiu-se que seria bastante difícil de atingir essa meta até o ano 2.000, a partir dos dados das safras de 1995, dadas as condições atuais de tecnologia, estrutura de posse da terra e politicas econômicas mais voltadas para as questões da estabilização econômica do que para a aceleração da produção agropecuária, via crédito abundante e barato.

\subsection{A produção brasileira e gaúcha dos principais grãos, 1970/95}

Entre 1970 e 1995, a produção que mais cresceu foi a de soja, tanto no Brasil, como no Rio Grande do Sul. Apesar do aumento da produção de soja no Brasil ter sido obtido basicamente pela expansão da área cultivada, foi a cultura que apresentou, no mesmo período, a maior taxa média de crescimento qüinqüenal do rendimento físico (ver Tabela 1). 
No Rio Grande do Sul, o rendimento da soja cresceu quase no mesmo ritmo da produção de milho $(21,5 \%)$. No caso desta última cultura, o aumento da produção no RS deveu-se basicamente à melhoria da produtividade, uma vez que a área cultivada permaneceu praticamente constante. Em termos de melhoria da produtividade, a cultura do milho ainda apresenta grandes possibilidades pelo uso mais generalizado de irrigação e plantio direto na paiha.

A taxa média de crescimento qüinqüenal do rendimento do arroz irrigado cresceu $10,8 \%$ no RS, no período, sendo de apenas $5,4 \%$ no caso do trigo. Esta última cultura, no entanto, apresenta amplas possibilidades de crescimento em termos de aumento da área cultivada, tendo em vista que o plantio é realizado no inverno, não havendo, portanto, outras culturas concorrentes com alguma relevância.

A produção de trigo no Brasil foi de 1,9 milhão de toneladas em 1970 , atingindo 3,8 milhões de toneladas em 1985 e apenas 1,5 milhão em 1995 Neste último ano, a área cultivada com essa cultura foi de apenas um milhão de ha, isto é, a metade da área de 1970 (2,06 milhões de ha). No RS a produção de trigo foi de 1,6 milhão de t em 1970, declinando a 904 mil t em 1985 e a 336 mil t em 1995 (Souza, 1996a, p.41-42). O declínio da safra brasileira de trigo explica-se, em grande parte, pela concorrência das importações de trigo mais barato da Argentina, Canadá e Estados Unidos e pela redução dos subsídios à agricultura no Brasil.

Tabela 1. Taxa média de crescimento qüinqüenal da produção, área cultivada e rendimento físico de arroz, milho, soja e trigo, Brasil e RS, 1970/1995 (\%)

\begin{tabular}{l|c|c|c|c|c|c}
\hline \multirow{2}{*}{$\begin{array}{l}\text { Pro- } \\
\text { duto }\end{array}$} & \multicolumn{3}{|c|}{ Brasil } & \multicolumn{3}{c}{ Rio Grande do Sul } \\
\cline { 2 - 7 } & $\begin{array}{l}\text { Quantidade } \\
\text { produzida }\end{array}$ & $\begin{array}{l}\text { Área } \\
\text { cultivada }\end{array}$ & $\begin{array}{l}\text { Rendimento } \\
\text { físico }\end{array}$ & $\begin{array}{l}\text { Quantidade } \\
\text { produzida }\end{array}$ & $\begin{array}{l}\text { Área } \\
\text { cultivada }\end{array}$ & $\begin{array}{l}\text { Rendimento } \\
\text { físico }\end{array}$ \\
\hline Arroz & 19,1 & 2,0 & 16,5 & 32,3 & 18,5 & 10,8 \\
Milho & 21,7 & 3,4 & 18,1 & 24,5 & 0,9 & 220 \\
Soja & 97,6 & 48,2 & 23,5 & 54,4 & 19,3 & 21,5 \\
Trigo & 5,0 & $-2,8$ & 19,2 & $-18,4$ & $-23,2$ & 5,4 \\
\hline
\end{tabular}

Fonte: Souza (1996a, p 40 a 43)

Obs : Média das variações percentuais de cada cinco anos, entre 1970/95

A Tabela 2 mostra que o acréscimo de 30 milhões de toneladas de grãos no Brasil pode ser obtido com aumento tanto da área cultivada, como do rendimento físico. No caso da área cultivada, supõe-se aumento de apenas $10 \%$ da área com arroz e soja, $20 \% \mathrm{com}$ milho e duplicação da área atual com trigo (ocupando-se os 2 milhões de ha de 1970).

Com relação ao rendimento físico, a suposição é de que aumente apenas $10 \%$ no caso da soja e do trigo, tendo em vista os ganhos substanciais de produtividade já alcançados por essas culturas, entre 1990/95. No caso do arroz $(24 \%)$ e do milho (31\%) esperam-se maiores gantos de produtividade nos próximos anos, tendo em vista as possibilidades de uso mais generalizado de 
irrigação na Região Sul, Brasil Central e Vale do São Francisco. Entre 1990/95, a taxa de crescimento do rendimento físico, no Brasil, foi de $42 \%$ para o arroz e $47,7 \%$ para o milho (Souza, 1996a, p. 41).

Tabela 2.

Estimativa da produção brasileira de arroz, milho, soja e trigo no ano 2000.

\begin{tabular}{|c|c|c|c|c|c|c|c|c|c|}
\hline $\begin{array}{l}\text { Pro- } \\
\text { dutos }\end{array}$ & $\begin{array}{l}\text { Coefi- } \\
\text { cíente } \\
\text { de } \\
\text { Área } \\
\end{array}$ & $\begin{array}{c}\text { Área de } \\
1995 \\
\text { (mil ha) }\end{array}$ & $\begin{array}{c}\text { Area de } \\
2000 \\
\text { (mil ha) }\end{array}$ & $\begin{array}{l}\text { Coefi- } \\
\text { ciente } \\
\text { de } \\
\text { Rend. }\end{array}$ & $\begin{array}{l}\text { Rendi- } \\
\text { mento } \\
1995 \text { * }\end{array}$ & $\begin{array}{l}\text { Rendi- } \\
\text { mento } \\
2.000^{*}\end{array}$ & $\begin{array}{l}\text { Produção } \\
\text { de } 2.000 \\
\text { (mil t) }\end{array}$ & $\begin{array}{l}\text { Produ- } \\
\text { ção de } \\
1.995 \\
\text { (mil t) }\end{array}$ & $\begin{array}{l}\text { Variação } \\
\% \text { da pro- } \\
\text { dução } \\
2000 / 1995\end{array}$ \\
\hline Arroz & $\overline{1,1}$ & 4.434 & 4.877 & 1,24 & 2.534 & 3.143 & 15.326 & 11.236 & 36,4 \\
\hline Milho & 1,2 & 12.494 & 14.993 & 1,31 & 2.623 & 3.436 & 51.519 & 32.773 & 57,2 \\
\hline Soja & 1,1 & 11.680 & 12.847 & 1,1 & 2.190 & 2.409 & 30.953 & 25.581 & 21,0 \\
\hline Trigo & 2,0 & 1.024 & 2.047 & 1,1 & 1.481 & 1.629 & 3.336 & 1.516 & 120,0 \\
\hline TOTAL & & & & & & & 101.134 & 71.106 & 42,2 \\
\hline \multicolumn{2}{|c|}{ Variação da } & produção & total & no ano & 2.000 & & 30.028 & - & - \\
\hline
\end{tabular}

Fonte: Souza (1996a, p 44).

Nota: * Rendimento dado em kg/ha

Assim, entre 1995/2000, o aumento da produção brasileira de grãos de 30 milhões de toneladas, passando-se dos atuais 71,1 milhões de toneladas, para 101,1 milhões de toneladas $(+42,2 \%)$, seria assim distribuído: soja $(21 \%)$; arroz $(36,4 \%)$; milho $(57,2 \%)$ e trigo $(120 \%)$.

Para o Rio Grande do Sul, considerou-se a possibilidade de expandir a área cultivada de arroz e soja em apenas $10 \%$ até o ano 2.000 , em relação a 1995. Entre 1990/95, a área com arroz cresceu $41,5 \%$ e a área com soja reduziu-se $14,5 \%$. Entretanto é possível que a área com arroz cresça bem mais do que $10 \%$, dependendo dos estímulos de mercado e da disponibilidade de água para irrigação.

Já faz algum tempo que se houve falar que a fronteira agricola esgotou-se no Rio Grande do Sul. Porém, levando-se em conta a possibilidade de adoção de pastagem cultivada e criação de gado em sistema de semiconfinamento, constata-se que ainda existem muitas terras disponiveis no RS, principalmente na fronteira Oeste. No Município de Dom Pedrito, por exemplo, ainda existem muitas áreas próprias para pastagens e rotação com cultivo de arroz e soja (principalmente o solo do tipo Ponche Verde, assim como o solo do tipo Vacacai, ao longo dos cursos d'água, nas várzeas).

O Município de Dom Pedrito cultiva apenas cerca de $1 / 6$ do total de suas várzeas com arroz ( 34.500 ha/180.000 ha), uma vez que a expansão da cultura arrozeira encontra-se bloqueada na região pela escassez de água para irrigação. No conjunto do Município, a lavoura de arroz ocupa apenas $7 \%$ da área aproveitável total (Souza, 1996b, p. 119). Nos demais municípios da Fronteira Oeste do Estado a situação não é muito diferente. 
Tabela 3.

Estimativa da produção gaúcha de arroz, milho, soja e trigo no ano 2000.

\begin{tabular}{|c|c|c|c|c|c|c|c|c|c|}
\hline $\begin{array}{l}\text { Pro- } \\
\text { duto }\end{array}$ & \begin{tabular}{|l|} 
Coefi \\
- \\
ciente \\
de \\
Área \\
\end{tabular} & $\begin{array}{c}\text { Área de } \\
1995 \\
\text { (mil ha) }\end{array}$ & $\begin{array}{l}\text { Area } \\
2000 \\
\text { (mil } \\
\text { ha) }\end{array}$ & $\begin{array}{l}\text { Coefi- } \\
\text { ciente } \\
\text { de } \\
\text { Rend }\end{array}$ & $\begin{array}{l}\text { Rendi- } \\
\text { mento } \\
1.995^{*}\end{array}$ & $\begin{array}{l}\text { Rendi- } \\
\text { mento } \\
2.000^{\star}\end{array}$ & $\begin{array}{l}\text { Produção } \\
\text { de } 2.000 \\
\text { (mil t) }\end{array}$ & $\begin{array}{l}\text { Produ- } \\
\text { ção de } \\
1995 \\
\text { (mil t) }\end{array}$ & $\begin{array}{l}\text { Variação } \\
\% \quad \text { da } \\
\text { produção } \\
2000 / 199 \\
5\end{array}$ \\
\hline $\begin{array}{l}\text { Arroz } \\
\text { Milho } \\
\text { Soja } \\
\text { Trigo } \\
\end{array}$ & $\begin{array}{l}1,10 \\
1,15 \\
1,10 \\
3,70 \\
\end{array}$ & $\begin{array}{r}992 \\
1.884 \\
3.009 \\
299 \\
\end{array}$ & $\begin{array}{l}1.091 \\
2.166 \\
3.309 \\
1.106 \\
\end{array}$ & $\begin{array}{c}1,1 \\
1,22 \\
1,1 \\
1,35 \\
\end{array}$ & $\begin{array}{l}5.081 \\
3.151 \\
1.944 \\
1.125 \\
\end{array}$ & $\begin{array}{l}5.589 \\
3.844 \\
2.138 \\
1.518 \\
\end{array}$ & $\begin{array}{l}6.096 \\
8.328 \\
7.076 \\
1.679 \\
\end{array}$ & $\begin{array}{r}5.038 \\
5.936 \\
5.848 \\
336 \\
\end{array}$ & $\begin{array}{r}21,0 \\
40,3 \\
21,0 \\
399,5 \\
\end{array}$ \\
\hline \multicolumn{7}{|l|}{ TOTAL } & 23.179 & 17.158 & 35,1 \\
\hline $\begin{array}{l}\text { Variaçã } \\
\text { o }\end{array}$ & da & $\begin{array}{c}\text { produçã } \\
0 \\
\end{array}$ & total & ano & 2.000 & & 6.021 & - & - \\
\hline
\end{tabular}

Fonte: Souza (1996a, p 46)

Nota: * Rendimento dado em $\mathrm{kg} / \mathrm{ha}$.

Para o milho, a suposição é a de que sua área aumente $15 \%$, a mesma taxa de crescimento dos últimos dez anos. Já para o trigo, a suposição foi a de que a área ocupada aumente 3,7 vezes no RS. Do ponto de vista físico, a possibilidade é bastante viável, tendo em vista que em 1995 cultivavam-se no Estado apenas 299 mil ha, isto é, $17,9 \%$ da área ocupada em 1970, que foi de 1,7 milhão de ha. Verificando-se esse aumento da produção de trigo, ele ainda ficaria $14 \%$ abaixo daquele verificado em 1980, que foi de 1,3 milhão de toneladas. O grande obstáculo para o aumento da produção de trigo nessa magnitude é o econômico, tendo em vista os atuais custos de produção e a concorrência do trigo importado.

Desse modo, as suposições, principalmente em relação ao trigo, foram efetuadas considerando-se a existência de estímulos governamentais para o setor agricola. No caso do trigo, além de seu grande poder de encadeamento ao longo da cadeia produtiva, que começa pelos moinhos no interior do País, há o relevante detalhe de ser uma cultura de inverno, época em que as terras ficam ociosas, justificando-se a sua produção, mesmo com custos médios de produção relativamente elevados.

Quanto ao rendimento físico, considerou-se um aumento de apenas $10 \%$ para o arroz e a soja, tendo em vista que essas duas culturas já atingiram niveis relativamente elevados no RS. Para o milho, supôs-se uma expansão de $22 \%$ entre $1995 / 2000$, tendo-se em vista as possibilidades de irrigação e plantio direto na palha, que também reduz os custos de produção. A taxa de crescimento de $35 \%$, projetada para o rendimento do trigo, justifica-se porque essa cultura já atingiu niveis mais elevados de produtividade, no passado.

A taxa média de crescimento anual, entre 1995/2000, no RS, precisaria ser de $21 \%$ para o arroz e a soja, $40,3 \%$ para o milho (vinculado também ao dinamismo da demanda da avicultura e suinocultura) e $399,5 \%$ para o caso do trigo, a fim de se atingir o aumento de seis milhões de toneladas de grãos, isto 
é, dos atuais 17,2 milhões de toneladas, para 23,2 milhões de toneladas no ano $2.000(+35,1 \%)$

Dessa forma, tendo em vista a evolução da área ocupada, da produção e da produtividade, para cada cultura, considerou-se bastante viável o crescimento da oferta de grãos no Rio Grande do Sul de seis milhões de toneladas e de 30 milhões de toneladas no Brasil em seu conjunto. Esta última simulação parece ser bem mais factivel do que aquela para o RS, tendo em vista as amplas áreas a serem ocupadas em todo o Brasil Central.

Além disso, considerando que a produtividade brasileira é bastante inferior à média gaúcha, há muitas possibilidades de se aumentar a produção da agricultura brasileira via aumento da produtividade. Por exemplo, no caso do arroz de sequeiro, que está sendo gradativamente substituido por arroz irrigado em muitas áreas, tendo em vista o seu menor rendimento e pouca aceitação no mercado (a preferência do consumidor é maior para o arroz tipo "agulhinha"), a tendência é o aumento da área plantada com arroz irrigado em amplas áreas de Mato Grosso do Sul e de Goiás.

No caso do milho, tanto no RS, como em outras áreas do Brasil, abrem-se amplas possibilidades de uso generalizado de insumos modernos, novas variedades e irrigação, podendo triplicar a produtividade. A adoção dessas inovações dependerá de estímulos de preços e crédito mais abundante para a compra de equipamentos de irrigação, máquinas, sementes etc.

A produção de soja poderá aumentar marginalmente no RS e um pouco mais no Brasil. Já para o trigo, existem amplas possibilidades, tanto no RS, como no Paraná, pela existência de terras ociosas no inverno e que poderão ser utilizadas amplamente para triplicar ou quadruplicar a sua produção. Tudo dependerá de preços estimuladores e de políticas governamentais favoráveis para o seu desenvolvimento.

\subsection{Impactos na economia brasileira e gaúcha no ano 2.000}

Assim, conhecendo-se a variação da quantidade produzida $(X)$ de arroz, milho, soja e trigo, para o RS e para o Brasil, entre 1995 e o ano 2000, estimouse o impacto sobre a produção, o valor adicionado e o emprego.

Partindo-se da equação $X=(I \cdot A)^{-1} F=K F$, onde $A$ é a matriz dos coeficientes diretos de insumos e $K$ é a matriz dos coeficientes diretos e indiretos, por unidade de variação da demanda final $(F)$, chegou-se aos impactos desejados, tanto para o RS, como para o Brasil, utilizando-se as matrizes respectivas, como será visto a seguir.

\subsubsection{Impactos sobre o valor da produção}

Em primeiro lugar, simularam-se variações no vetor de demanda final, $F$, tentativamente, de sorte a resultar as variações esperadas na produção de 
arroz, milho, soja e trigo, conforme a última coluna das Tabelas 2 e 3 . O vetor $F$, de 1995, foi obtido pela aplicação das taxas de crescimento setoriais fornecidas pelo IBGE e pela Fundação de Economia e Estatística do RS. O vetor $X_{1995}$ foi estimado pela multiplicação da matriz $K_{1991}$ pelo $F_{1995}$ : desse modo, $X_{1995}$ já ficou ajustado à matriz $K_{1991}$ calculada e passível de comparação com o $X_{2000}$. O $F_{2000}$ é aquele que gera um $X_{2000}$ compatível com as variações desejadas da produção de arroz, milho, soja e trigo.

Como é relativamente mais difícil obter-se uma variação de 6 milhões de $t$ de grãos no RS, do que 30 milhões de t conjunto do Brasil, é de se esperar que os impactos sejam proporcionalmente mais importantes na economia gaúcha do que em nivel nacional.

De fato, os 30 milhões de $\mathrm{t}$ de grãos fazem variar o valor da produção nacional em apenas $1,15 \%$ (Tabela 4). No inicio dessa tabela, encontram-se os quatro produtos que provocaram os impactos no período. Registre-se que, por hipótese, tudo o mais permanece constante: esse é o efeito líquido de variações exógenas havidas apenas na produção desses quatro produtos.

A seguir, os produtos com as maiores variações induzidas são Adubos $(8,61 \%)$, Outros produtos químicos $(4,21 \%)$, Leite natural $(2,69 \%)$, Café em coco $(2,45 \%)$, Aves vivas $(1,93 \%)$, Outros alimentos $(1,87 \%)$ (Para os produtos com impactos inferiores a 1\%, ver Souza,1996a).

Como no caso do RS, Adubos e Outros produtos químicos são os produtos alimentares os que apresentam os maiores impactos. Isso se explica pelas interdependências tecnológicas indiretas existentes entre os quatro produtos básicos, cuja produção variou inicialmente, com insumos industriais, sementes e alimentos. Além disso, sendo a agricultura um setor que emprega elevado contingente de pessoas, é natural que haja crescimento expressivo de outros alimentos para atender a maior demanda dos novos trabalhadores empregados e de sua família. 
Tabela 4. Valor da produção brasileira por produto, em 1995

e no ano 2.000 , e variação percentual a partir do aumento na produção de arroz, milho, soja e trigo em 30 milhões de $t$ ( $C r \$$ milhões de 1985)

\begin{tabular}{l|c|c|r|r}
\hline \multicolumn{1}{c|}{ PRODUTOS } & $\begin{array}{c}\text { PRODUÇÁO } \\
\text { EM } 1995\end{array}$ & $\begin{array}{c}\text { PRODUÇÃO } \\
\text { ANO 2.000 }\end{array}$ & $\begin{array}{r}\text { VARIAÇÃO } \\
2000 / 1995\end{array}$ & $\begin{array}{l}\text { VARIAÇÃO } \\
\%\end{array}$ \\
\hline Trigo em grão & 8.888 & 19.553 & 10.665 & 2,2000 \\
Milho em grão & 9.226 & 14.503 & 5.277 & 1,5720 \\
Arroz em casca & 9.867 & 13.458 & 3.591 & 1,3640 \\
Soja em grão & 15.630 & 18.912 & 3.282 & 1,2100 \\
Adubos & 17.034 & 18.501 & 1.467 & 1,0861 \\
Outros produtos quimicos & 18.833 & 19.627 & 794 & 1,0421 \\
Leite natural & 18.972 & 19.481 & 509 & 1,0269 \\
Café em coco & 21.045 & 21.561 & 516 & 1,0245 \\
Aves vivas & 16.641 & 16.963 & 322 & 1,0193 \\
Outros alimentos (e ração) & 42.430 & 43.223 & 793 & 1,0187 \\
Oleos combustiveis, diesel & 40.998 & 41.624 & 626 & 1,0153 \\
Prod. petroquímicos básicos & 24.609 & 24.969 & 360 & 1,0147 \\
Prod. quimicos não petroquím. & 12.008 & 12.180 & 172 & 1,0143 \\
Outros prod agropecuários & 73.937 & 74.923 & 986 & 1,0133 \\
Cana-de-açúcar & 17.099 & 17.319 & 220 & 1,0129 \\
Óleos vegetais brutos & 24.430 & 24.716 & 286 & 1,0117 \\
Outros prod. minerais & 21.110 & 21.333 & 223 & 1,0105 \\
Petróleo e gás & 33.352 & 33.703 & 351 & 1,0105 \\
Farinha de trigo & 6.404 & 6.471 & 67 & 1,0105 \\
PRODUÇÃO TOTAL & 3.206 .003 & 3.242 .903 & 36.900 & 1,0115 \\
\hline
\end{tabular}

Fonte: Souza (1996a)

Registre-se também a presença entre esses 19 produtos com os maiores impactos, além dos produtos mencionados, também Óleos combustíveis/ óleo diesel, Produtos petroquímicos básicos, Produtos químicos não petroquimicos, Outros produtos minerais e Petróleo/gás.

Setorialmente, o aumento da produção total brasileira em 1,15\% distribui-se da seguinte maneira: Agropecuária, 10,68\%; Química/ petroquimica, 1,35\%; Produtos alimentares, $0,59 \%$; Produtos e serviços diversos, $0,47 \%$, MetalMecânica, 0,25\% e Madeira, papel e papelão, 0,24\% (Souza, 1996a, p. 48).

O impacto do aumento de seis milhões de toneladas de grãos no RS representa um aumento de $7,32 \%$ do valor da produção total, tudo o mais permanecendo constante (Tabela 5). Além dos quatro gêneros com as variações iniciais, os produtos com os maiores impactos seriam Adubos $(42,37 \%)$, Bovinos e suinos $(32,85)$, Outros produtos químicos $(22,3 \%)$, Leite natural $(19,9 \%)$ etc. No conjunto, são 10 produtos agroalimentares que apresentam elevados impactos em decorrência de uma elevação exógena da produção gaúcha de grãos. 
Tabela 5. Valor da Produção gaúcha por produto, em 1995 e no ano 2.000 , e variação percentual a partir do aumento na produção de arroz, milho, soja e trigo em 6 milhões de $t$ (Cr\$ milhões de 1985)

\begin{tabular}{|c|c|c|c|c|}
\hline PRODUTOS & $\begin{array}{c}\text { PRODUÇẨO } \\
\text { EM } 1995 \\
\end{array}$ & $\begin{array}{l}\text { PRODUUCAOA } \\
\text { ANO } 2.000 \\
\end{array}$ & $\begin{array}{l}\text { VARIAÇẢO } \\
2000 / 1995 \\
\end{array}$ & 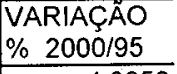 \\
\hline Trigo em grão & 2.158 & 10.778 & 8.620 & 4,9950 \\
\hline Adubos & 1.712 & 2.438 & 726 & 1,4237 \\
\hline Milho em grão & 6.226 & 8.736 & 2.510 & 1,4030 \\
\hline Bovinos e suinos & 1.666 & 2.213 & 547 & 1,3285 \\
\hline Outros produtos químicos & 356 & 436 & 80 & 1,2232 \\
\hline Arroz em casca & 4.172 & 5.049 & 877 & 1,2100 \\
\hline Soja em grão & 5.642 & 6.827 & 1.185 & 1,2100 \\
\hline Leite natural & 2.358 & 2.828 & 470 & 1,1990 \\
\hline Cana-de-açúcar & 249 & 289 & 40 & 1,1604 \\
\hline Óleos vegetais brutos & 2.248 & 2.541 & 293 & 1,1306 \\
\hline Outros alimentos (e ração) & 2.386 & 2.663 & 277 & 1,1159 \\
\hline Outros prod. agropecuários & 6.715 & 7.314 & 599 & 1,0892 \\
\hline Óleos combustíveis e diesel & 4.404 & 4.768 & 364 & 1,0826 \\
\hline Prod químicos não petroq & 117 & 127 & 10 & 1,0804 \\
\hline Prod petroquímicos básicos & 6.415 & 6.885 & 470 & 1,0733 \\
\hline Aves vivas & 2.728 & 2919 & 191 & 1,0701 \\
\hline Outros produtos minerais & 439 & 463 & 24 & 1,0558 \\
\hline Farinha de trigo & 1.286 & 1.350 & 64 & 1,0503 \\
\hline Outros produtos do refino & 1.192 & 1.244 & 52 & 1,0439 \\
\hline Margem de transporte & 10.850 & 11.248 & 398 & 1,0367 \\
\hline Resinas & 2.975 & 3.062 & 87 & 1,0292 \\
\hline Prod farmac., perfumaria & 635 & 650 & 15 & 1,0242 \\
\hline Outros produtos texteis & 463 & 474 & 11 & 1,0233 \\
\hline Serv ind de utilidade pública & 6700 & 6.851 & 151 & 1,0226 \\
\hline Serv prestados às empresas & 6.586 & 6.731 & 145 & 1,0221 \\
\hline Tintas & 448 & 457 & 9 & 1,0204 \\
\hline Carvão e derivados & 94 & 96 & 2 & 1,0200 \\
\hline Margem de comércio & 11.986 & 12.219 & 233 & 1,0194 \\
\hline Gasoálcool & 1.293 & 1.317 & 24 & 1,0181 \\
\hline Produtos diversos & 5.197 & 5.290 & 93 & 1,0179 \\
\hline Artigos de plástico & 1.207 & 1.228 & 21 & 1,0170 \\
\hline Outros serviços & 4.963 & 5.047 & 84 & 1,0170 \\
\hline Açúcar & 297 & 302 & 5 & 1,0168 \\
\hline Fab e manut máq e equip. & 8.379 & 8.513 & 134 & 1,0160 \\
\hline Papel,celul., pap e derivados & 2.092 & 2.123 & 31 & 1,0149 \\
\hline Gasolina pura & 730 & 741 & 11 & 1,0148 \\
\hline Óleos vegetais refinados & 1.715 & 1.739 & 24 & 1,0141 \\
\hline Fios têxteis naturais & 409 & 415 & 6 & 1,0130 \\
\hline Prod siderúrgicos básicos & 4.999 & 5.059 & 60 & 1,0121 \\
\hline Outros veículos e peças & 1.755 & 1.775 & 20 & 1,0111 \\
\hline Comunicações & 4.222 & 4.267 & 45 & 1,0107 \\
\hline Prod derivados da borracha & 1.940 & 1.960 & 20 & 1,0102 \\
\hline PRODUÇÃO TOTAL & 63.720 & 283.033 & 19.313 & 1,0732 \\
\hline
\end{tabular}

Fonte: Souza (1996a).

Enquanto a economia brasileira possui 19 produtos com impactos superior a $1 \%$, a economia gaúcha apresenta 42, destacando-se, além dos produtos já enumerados, Óleos combustiveis e óleo diesel $(8,26 \%)$, 
Produtos químicos não petroquímicos $(8,04 \%)$, Produtos petroquímicos básicos $(7,33 \%)$, Outros produtos minerais $(5,58 \%)$, entre outros. Em termos absolutos, as maiores variações da produção ocorreriam com o Trigo, Milho, Soja, Arroz e Adubos. $^{2}$

Constata-se, assim, que a economia gaúcha continua muito integrada com o setor agropecuário, de sorte que a agricultura ainda representa uma grande parcela de sua atividade econômica. Setorialmente, portanto, observa-se que a produção agropecuária aumentaria $47,12 \%$, contra 8,06 para a Químicapetroquímica, $2,88 \%$ para Produtos alimentares, $1,43 \%$ para Produtos $\mathrm{e}$ serviços diversos, 1,29\% para a Metal-mecânica e 0,95\% para o setor Madeira, papel e papelão (Souza, 1993a, p. 50).

\subsubsection{Impactos sobre o valor adicionado}

Os impactos no valor adicionado foram calculados pela fórmula $V_{1995}=V$ $X_{1995}=V_{d} K_{1991} F_{1995}$, sendo $V_{1995} O$ vetor do valor adicionado de $1995, v o$ vetor dos coeficientes de valor adicionado e $v_{d}$ a matriz diagonal desses coeficientes.

Tabela 6. Valor adicionado do Brasil, por setor, em 1995 e no ano 2.000 , e variação percentual a partir do aumento na produção de arroz, milho, soja e trigo em 30 milhões de $t$ (CR\$ milhões de 1985)

\begin{tabular}{l|r|r|r|r}
\hline \multicolumn{1}{c|}{ SETORES } & $\begin{array}{c}\text { Valor } \\
\text { Adicionado do } \\
\text { ano } 1.995\end{array}$ & $\begin{array}{c}\text { Valor } \\
\text { Adicionado } \\
\text { do ano } 2.000\end{array}$ & $\begin{array}{l}\text { VARIAÇẢO } \\
2000 / 1995\end{array}$ & $\begin{array}{c}\text { VARIAÇÃO } \\
\%\end{array}$ \\
\hline Agropecuária & 151.040 & 167.152 & 16.112 & 1,1067 \\
Química-Petroquimica & 155.140 & 157.226 & 2.086 & 1,0134 \\
Produtos Alimentares & 61.553 & 61.972 & 419 & 1,0068 \\
Prod. e Serviços Diversos & 76.717 & 77.089 & 372 & 1,0048 \\
Metal-Mecánica & 46.575 & 46.693 & 118 & 1,0026 \\
Madeira e Papel e papelão & 88.307 & 88.529 & 222 & 1,0025 \\
Material Transporte & 1.075 .525 & 1.077 .818 & 2.293 & 1,0021 \\
Téxtil-Vestuário-Calçados & 44.317 & 44.392 & 75 & 1,0017 \\
Extrmmineral/miner.não met & 30.226 & 30.262 & 36 & 1,0012 \\
Elétrico-Eletrônico & 37.285 & 37.298 & 13 & 1,0004 \\
VALOR ADICIONADO TOTAL & 1.766 .684 & 1.788 .432 & 21.748 & 1,0123 \\
\hline
\end{tabular}

Fonte: Souza (1996a).

O impacto sobre o valor adicionado do Brasil é um pouco superior ao que ocorreu com o valor da produção $(1,23 \%$, contra $1,15 \%)$, mas mantém a coerência entre os setores (Tabela 6). A agropecuária aumenta 10,67\%, seguida pela Quimica/petroquimica $(1,34 \%)$, pela Extrativa mineral/ minerais não metálicos $(0,68 \%)$ e Produtos alimentares $(0,48 \%)$.

\footnotetext{
${ }^{2}$ A relação completa dos impactos por produto encontra-se em Souza (1996a).
} 
As maiores variações do valor adicionado, em termos absolutos, são as da Agropecuária, Material de transporte, Química/petroquímica, Produtos alimentares e Produtos e serviços diversos.

Os setores com menor impacto percentual sobre o valor adicionado são Elétrico/eletrônico $(0,04 \%)$, Material de transporte $(0,12 \%)$ e Têxtil/vestuário/calçados $(0,17 \%)$. Apesar dessas pequenas variações, a simulação serve para mostrar as interdependências entre os setores produtivos e que variações de produtos tão diferentes como milho e produtos eletrônicos acabam interagindo no fim da cadeia produtiva.

A Tabela 7 mostra os impactos setoriais sobre o valor adicionado da economia gaúcha, a partir do aumento da produção de grãos em seis milhões de toneladas entre 1995 e o ano 2.000. O impacto sobre o valor adicionado da agropecuária foi de $47,1 \%$, aproximadamente o mesmo impacto no caso do valor da produção.

Após a Agropecuária, os maiores impactos percentuais sobre o valor adicionado ocorriam nos setores Químico/petroquímico $(8,08 \%)$, Produtos alimentares $(2,86 \%)$ e Produtos e serviços diversos $(1,75 \%)$. Em termos absolutos, o setor Químico/petroquímico continua com os maiores impactos, seguido de Madeira/papel/papelão. No conjunto, o valor adicionado da economia gaúcha aumentaria $7,85 \%$, a partir dessa variação da produção de grãos em seis milhões de toneladas.

Tabela 7. Valor adicionado do Rio Grande do Sul, por setor, em 1995 e no ano 2000 , e variação percentual a partir do aumento na produção de arroz, milho, soja e trigo em 6 milhōes de $t(C r \$$ milhões de 1985)

\begin{tabular}{|c|c|c|c|c|}
\hline SETORES & $\begin{array}{c}\text { Valor } \\
\text { Adicionado do } \\
\text { ano } 1.995 \\
\end{array}$ & $\begin{array}{c}\text { Valor } \\
\text { Adicionado } \\
\text { do ano } 2.000 \\
\end{array}$ & $\begin{array}{l}\text { VARIAÇÃO } \\
2000 / 1995\end{array}$ & $\begin{array}{c}\text { VARIAÇÂO } \\
\% \\
2000 / 1995 \\
\end{array}$ \\
\hline Agropecuária & 19.916 & 29.295 & 9.379 & 1,4710 \\
\hline Química-Petroquímica & 11.249 & 12.158 & 909 & 1,0808 \\
\hline Produtos Alimentares & 6.546 & 6.733 & 187 & 1,0286 \\
\hline Prod e Serviços Diversos & 929 & 946 & 17 & 1,0175 \\
\hline Metal-Mecânica & 7.282 & 7.379 & 97 & 1,0133 \\
\hline Madeira e Papel e papelão & 89.312 & 90.138 & 826 & 1,0092 \\
\hline Material Transporte & 943 & 952 & 9 & 1,0089 \\
\hline Têxtil-Vestuário-Calçados & 2.373 & 2.391 & 18 & 1,0075 \\
\hline Extr.min /minerais não met. & 1.060 & 1.062 & 2 & 1,0021 \\
\hline Elétrico-Eletrônico & 6.230 & 6.241 & 11 & 1,0019 \\
\hline VALOR ADICIONADO TOTAL & 145.839 & 157.295 & 11.456 & 1,0785 \\
\hline
\end{tabular}

Fonte. Souza ('1996a)

\subsubsection{Impactos sobre o nivel de emprego}

Da mesma forma, foram calculados os impactos sobre o nível de emprego por produto e por setor, pela fórmula $E_{1995}=$ e $X_{1995}=e_{d} K_{1991} F_{1995}$, sendo $E_{1995}$ $o$ vetor do emprego de 1995 , e o vetor dos coeficientes de emprego e $e_{d}$ a 
matriz diagonal desses coeficientes. Os vetores $V_{2000}$ e $E_{2000}$ foram obtidos em função de $F_{2000}$, da matriz $K_{1991}$ e dos coeficientes técnicos respectivos.

Comparando-se o vetor $E_{2000}$ com o vetor $E_{1995}$, verificaram-se os impactos exercidos pelas variações projetadas na produção de grãos no Brasil e no Rio Grande do Sul, sobre o emprego por setor e por produto.

A Tabela 8 apresenta o impacto no nivel de emprego por setor da economia brasileira a partir de uma variação de 30 milhões de toneladas de grãos; no conjunto da economia, permanecendo tudo o mais constante, esse impacto seria de $2,22 \%$ sobre o total do emprego.

Obviamente, os maiores impactos ocorreriam na Agropecuária, cujo emprego aumentaria $11,6 \%$ em cinco anos, ou seja, mais 266.515 pessoas, ou $89,2 \%$ do impacto total (+ 298.838 empregos). Desse incremento de cerca de 300 mil novos empregos, mais de $1 / 3$ ocorreria na produção de trigo e mais de $42 \%$ na produção de arroz, milho e soja. ${ }^{3}$

Tabela 8. Nivel de emprego da economia brasileira, por setor, em 1995 e no ano 2.000 , e variação percentual a partir do aumento na produção de arroz, milho, soja e trigo em 30 milhões de $t$

\begin{tabular}{|c|c|c|c|c|}
\hline PRODUTOS & $\begin{array}{c}\text { Emprego } \\
\text { no ano } 1995\end{array}$ & $\begin{array}{c}\text { Emprego } \\
\text { no ano } 2.000\end{array}$ & $\begin{array}{l}\text { VARIAÇAO } \\
2000 / 1995\end{array}$ & $\begin{array}{l}\text { VARIAÇÅO } \\
\% \quad 2000 / 95\end{array}$ \\
\hline Agropecuária & 2.297 .451 & $2,563.966$ & 266515 & 1,1160 \\
\hline Quimica-Petroquimica & 133.367 & 134.906 & 1.539 & 1,0115 \\
\hline Produtos Alimentares & 178.265 & 179.689 & 1.424 & 1,0080 \\
\hline Prod. e Serviços Diversos & 87.592 & 87.948 & 356 & 1,0041 \\
\hline Metal-Mecânica & 317.714 & 318.612 & 898 & 1,0028 \\
\hline Madeira e Papel e papelão & 9.916916 & 9.944 .403 & 27.487 & 1,0028 \\
\hline Material Transporte & 50365 & 50.488 & 123 & 1,0025 \\
\hline Têxtil-Vestuário-Calçados & 232.463 & 232.761 & 298 & 1,0013 \\
\hline Extr mineral/miner não metálicos & 139.491 & 139.653 & 162 & 1,0012 \\
\hline Elétrico-Eletrônico & 85.051 & 85.087 & 36 & 1,0004 \\
\hline EMPREGO TOTAL & 13.438 .676 & 13.737 .514 & 298.838 & 1,0222 \\
\hline
\end{tabular}

Fonte: Souza (1996a, p 52 e 54)

A Química/petroquímica seria, a seguir, a indústria com o maior impacto relativo sobre o nivel de emprego (+ 1.539 ou $1,15 \%$ ), seguida de Produtos alimentares $(+1.424$, ou $0,8 \%)$ e de Produtos e serviços diversos ( +356 , ou $0,41 \%)$. No entanto, em termos absolutos, a indústria com o maior impacto absoluto sobre o nivel de emprego, depois da Agropecuária, seria Madeira/ pape e papelão, com mais 27.487 novos empregos criados $(+0,28 \%)$.

Embora os maiores impactos seriam produzidos no meio rural, pela natureza da simulação, constata-se que indústrias modernas, como a Química/petroquímica e a Metal-Mecânica, localizadas nos centros urbanos e industriais, também ficariam beneficiadas pelo aumento do consumo intermediário por parte da agricultura. Impactos significativos também

${ }^{3}$ Para os impactos relativos aos produtos, ver Souza (1996a, p. 52 e 53). 
ocorreriam em indústrias tradicionais, como Produtos alimentares e Madeira/papel/papelão/produtos derivados.

Já na economia gaúcha, o impacto total sobre o nivel de emprego seria de $6,66 \%$, a partir de uma variação de seis milhões de toneladas de grãos, correspondendo a 138.501 novos empregos (Tabela 9).

Tabela 9. Nivel de emprego do RS por setor, em 1995 e no ano 2.000 , e variação percentual a partir do aumento na produção de arroz, milho, soja e trigo em 6 milhões de $t$

\begin{tabular}{|c|c|c|c|c|}
\hline PRODUTOS & $\begin{array}{c}\text { Emprego } \\
\text { no ano } 1995\end{array}$ & $\begin{array}{c}\text { Emprego } \\
\text { no ano } 2.000\end{array}$ & $\begin{array}{l}\text { VARIAÇÅO } \\
2000 / 1995\end{array}$ & $\begin{array}{l}\text { VARIAÇẢO } \\
\% \text { 2000/95 }\end{array}$ \\
\hline Agropecuária & 303.013 & 412.846 & 109.833 & 1,3625 \\
\hline Química-Petroquimica & 52.363 & 55.489 & 3.126 & 1,0597 \\
\hline Produtos Alimentares & 71.772 & 75331 & 3.559 & 1,0496 \\
\hline Prod. e Serviços Diversos & 1.306 .377 & 1.325 .544 & 19.167 & 1,0147 \\
\hline Metal-Mecânica & 122.736 & 124.221 & 1.485 & 1,0121 \\
\hline Madeira e Papel e papeião & 20.278 & 20.487 & 209 & 1,0103 \\
\hline Material Transporte & 56.161 & 56.617 & 456 & 1,0081 \\
\hline Têxtil-Vestuário-Calçados & 93.593 & 94.127 & 534 & 1,0057 \\
\hline Extr mineral/miner não metálicos & 19.568 & 19.628 & 60 & 1,0031 \\
\hline Elétrico-Eletrônico & 34.243 & 34.313 & 70 & 1,0021 \\
\hline EMPREGO TOTAL & 2.080 .103 & 2.218 .604 & 138.501 & 1,0666 \\
\hline
\end{tabular}

Fonte: Souza (1996a, p. 52 e 54).

O impacto sobre o nivel de emprego da Agropecuária gaúcha seria de $36,25 \%$, representando 109.833 novos empregos, ou $79,3 \%$ do impacto total (+ 138.501 novas ocupações). Somente a produção de trigo em grão geraria 55.039 novos empregos, cabendo a Bovinos/suinos e a Outros produtos agropecuários, respectivamente, a criação de 21.710 e de 10.226 novos postos de trabalho (Souza, 1996a, p. 53).

Como no caso da economia brasileira, seriam as indústrias QuimicaPetroquímica (+3.166, ou $5,97 \%$ ) e Produtos alimentares (+3.559, ou 4,96\%) que teriam, a seguir, os maiores impactos sobre o nivel de emprego. Em termos absolutos, a maior variação, após a Agropecuária, seria a de Produtos e serviços diversos (+ 19.167 , ou 1,47\%). Cabe destacar, ainda, o impacto sobre as indústrias Metal-Mecânica, com +1.485 novos postos de trabalho, correspondendo a uma variação de $1,21 \%$ no ano 2.000 em relação a 1995 , tudo o mais permanecendo constante.

A maior variação relativa ocorrida na economia gaúcha seria devido, em primeiro lugar, a uma variação exógena relativamente maior da produção de grãos em relação ao Brasil. Em segundo lugar, a economia gaúcha, embora relativamente bem industrializada, mostra-se bem mais articulada com o setor agropecuário do que o Brasil em seu conjunto, pela presença de grandes cooperativas e importantes agroindústrias.

A importância dos encadeamentos interindustriais de fora do complexo agroalimentar também pode ser vista pelos efeitos nos demais setores, que 
representaria mais 28.668 pessoas ocupadas, em um total de 138.501 novos postos de trabalho $(20,7 \%)$.

\section{CONSIDERAÇÕES FINAIS}

O modelo de insumo-produto é um importante instrumento para o planejamento econômico e o estudo de impactos de variações exógenas da demanda final, sobre o nivel do produto e emprego. No entanto a elaboração de matrizes mais desagregadas envolve altos custos para a obtenção dos dados, o que dificulta a disponibilidade de coeficientes de insumo-produto mais atualizados.

A atualização e regionalização de matrizes pelo método R.A.S., embora constitua uma projeçāo relativamente rudimentar dos "verdadeiros" coeficientes, tern se mostrado uma alternativa importante para os estudos de impactos setoriais e para simulação de novas situações econômicas.

Entre 1990/95, o crescimento da produção brasileira de arroz, milho e soja foi bastante expressivo, com substanciais ganhos de produtividade, mas continuou declinante a produção de trigo. No RS cresceram significativamente, nesse período, o cultivo de arroz e milho, mas foram negativas as taxas de crescimento das produções de soja e trigo, em face da redução dos subsídios. Em termos absolutos, o RS possuia, em 1995, o dobro do rendimento do arroz em relação ao Brasil ( $5.081 \mathrm{~kg} / \mathrm{ha}$, contra $2.534 \mathrm{~kg} / \mathrm{ha}$ ), enquanto para o milho o diferencial era de $3.151 \mathrm{~kg} / \mathrm{ha}$ para $2.623 \mathrm{~kg} / \mathrm{ha}$. Já para a soja e o trigo o rendimento foi menor: soja, $1.944 \mathrm{~kg} / \mathrm{ha}$, contra $2.190 \mathrm{~kg} / \mathrm{ha}$ e o trigo, 1.125 $\mathrm{kg} / \mathrm{ha}$ versus $1.481 \mathrm{~kg} / \mathrm{ha}$ (Souza, 1996a, p. 41 e 43).

A variação da produção brasileira em 30 milhões de $t$ de grãos $(4,1$ milhões de $t$ de arroz, 18,7 milhões de $t$ de milho, 5,4 milhões de $t$ de soja e 1,8 milhão de $t$ de trigo) seria possivel pela elevação do rendimento por unidade de área (irrigação, máquinas e insumos modernos) e, principalmente, pela ampliação da fronteira agricola, principalmente no Centro-Oeste e nos Cerrados. No caso do arroz, seria possivel o uso mais intenso de irrigação em amplas áreas no Mato Grosso do Sul e em Goiás, prática que já está ocorrendo nessas regiões.

No caso do RS, o aumento de 6,2 milhões de $t$ de grãos (1,1 millhão de $t$ de arroz, 2,4 milhões de $t$ de milho, 1,3 milhão de $t$ de soja e 1,4 milhão de $t$ de trigo) seria obtido pelo acréscimo de área ( $10 \%$ no caso do arroz e da soja, $15 \%$ no do milho e 3,7 vezes no do trigo) e de produtividade (10\% para o arroz e a soja, $22 \%$ para o milho e $35 \%$ para o trigo). O aumento da área com trigo, nessa magnitude, se justifica pela existência de extensas áreas desocupadas durante o inverno.

$\mathrm{Na}$ simulação para a economia brasileira, o aumento projetado elevaria o PIB em $1,15 \%$ (US $\$ 6,47$ bilhões), valor equivalente a $15 \%$ do PIB gaúcho de 1995. Saliente-se que essa simulação é líquida, isto é, considera crescimento zero para os demais produtos da economia. Como todos os produtos crescerão, 
os impactos na economia seriam ainda maiores.

No caso do RS, o impacto seria de $7,32 \%$ no PIB. Aplicando esse percentual ao PIB estimado para 1995 (US $\$ 42,9$ bilhões), o impacto seria de US $\$ 3,14$ bilhões, valor aproximado ao da produção agropecuária gaúcha de 1994. Contudo, para se atingir essa meta, seria necessária a adoção de uma política agricola bem-definida de longo prazo quanto a crédito com juros mais atraentes, principalmente para investimentos, estimulos à adoção de novas práticas de manejo do solo, seguro agricola mais abrangente e preços minimos mais remuneradores.

Elevando-se a produção agricola projetada, aumentaria o nivel de renda médio do meio rural e das pequenas e médias cidades do interior do Brasil. Estando também saneadas as finanças públicas municipais, o aumento da arrecadação pública, decorrente da dinamização da atividade econômica, elevaria a capacidade de investimento público em infra-estruturas econômicas e sociais, como contrapartida brasileira aos financiamentos internacionais, estimulando ainda mais as atividades econômicas das regiões e do Pais. Desse modo, torna-se possivel a ocorrência de um processo acumulativo ascendente de desenvolvimento à la Myrdal, o que ajudaria a reduzir os fluxos migratórios em direção das capitais estaduais.

Além da incorporação de novas áreas agrícolas ao processo produtivo, através da EMATER, EMBRAPA, SENAR, SEBRAE, Banco do Brasil e das Secretarias Estaduais da Agricultura, é de se esperar também um esforço conjunto no sentido de incrementar a produtividade da terra e do homem empregado, através de novos investimentos e da educação rural. Por exemplo, no segmento de hortigranjeiros é possível elevar substancialmente a produtividade do solo com o uso de irrigação em áreas cobertas. No caso do milho, pode-se triplicar o rendimento com o uso de irrigação e insumos modernos. Com relação ao arroz, o uso de sistematização do solo (eliminação de microrrelevos) aumentaria a produtividade e reduziria os custos com água, combustíveis, defensivos e mão-de-obra, elevando a margem de lucro e os incentivos à produção.

O aumento do emprego e da renda nas regiões periféricas incrementaria a demanda de bens de consumo duráveis e de bens de capital, estimulando as indústrias dos centros regionais e nacionais de crescimento. A elevação do nivel de renda e do emprego nas áreas periféricas, seguida de políticas sociais no sentido de melhoria do bem-estar do conjunto da população, como expansão da rede de água tratada e de esgotos, eletrificação rural, entre outras iniciativas, estariam aumentando os indicadores de desenvolvimento humano, podendo colocar o Brasil em posições mais favoráveis no contexto internacional. 


\section{BIBLIOGRAFIA}

LEÃO, A S. et. al. Matriz de insumo-produto do Brasil, 1970. Revista Brasileira de Economia, v. 27, n. 3, jul /set. 1973.

MATRIZ de relações intersetoriais de 1970: Brasil/Fundação Instituto Brasileiro de Geografia e Estatística. Rio de Janeiro: IBGE, 1979.

RELAÇÕ̃ES intersetoriais do Brasil (1959): Cadernos do IPEA, n. 2, dez. 1967.

SOUZA, Nali de Jesus $O$ papel da agricultura na integração intersetorial brasileira. São Paulo: IPE/USP, 1988. 321p. Tese (doutorado em Economia), USP.

O Método dos Dígrafos uma Aplicação para a Matriz de Relações Interindustriais do Brasil de 1975. Pesquisa e Planejamento Econômico, v. 19, n. 3, p. 613-41, dez. 1989

Desenvolvimento Econômico. São Paulo: Atlas, 1995.

Efeitos de Encadeamento da Agroindústria Alimentar Brasileira. Porto Alegre: CPGE/UFRGS, 1994 (Relatório de Pesquisa ao CNPq).

Estrutura produtiva, mudança tecnológica e desenvolvimento econômico: dimensionamento do complexo agroindustrial do Brasil e do Rio Grande do Sul. Porto Alegre: CPGE, 1996a (Relatório de Pesquisa não publicado).

Diagnóstico econômico do Municipio de Dom Pedrito. Porto Alegre:

FARSUL/SENAR, 1996b

ABSTRACT
METHODOLOGY OF PROJECTION AND OBTAINING OF REGIONAL
THE INPUT-OUTPUT MATRIX: THE IMPACT ON INCREASE IN THE GRAIN
PRODUCTION OF RIO GRANDE DO SUL AND BRAZILIAN'S ECONOMIES IN YEAR 2000
This paper presents the methodology to obtain the Brazilian input-output matrix by sectors or
by products using, as a starting point, the IBGE matrices, as well as the methodology of
projection and obtaining of regional matrices. It also evaluates the impact of a variation of 6 and
30 million tons in the grain production of, respectively, Rio Grande do Sul and Brazil, on total.
output and employment in the year 2000 .

